\title{
Comparison of inferior oblique muscle weakening by anterior transposition or myectomy: a prospective study of 20 cases
}

\author{
Byung-Moo Min, Ju-Hee Park, Seung-Young Kim, Seong-Bok Lee
}

\begin{abstract}
Backgroundlaims-Among the various weakening techniques of inferior oblique muscle overaction, the most commonly used techniques include myectomy, recession, and anterior transposition. Anterior transposition and myectomy were compared to evaluate the surgical results in inferior oblique overaction.

Methods-20 children with bilateral +3 overacting inferior oblique muscles underwent a prospective randomised study by which the anterior transposition procedure in one eye was compared with the myectomy procedure in the other eye.

Results-Postoperative follow up averaged 2 years. The success rates in two surgical procedures were $85 \%$ for the anterior transposition and $25 \%$ for the myectomy (standard of success was based on zero inferior oblique overaction). In only one case did the anterior transposition tend to limit the elevation of the eye in the midline, adduction, and abduction. Anterior transposition produced hypotropia at the primary position in only one case. Most eyes that underwent myectomy (75\%) showed apparent residual overaction.

Conclusion-The anterior transposition appeared to be more effective in eliminating the overaction of inferior oblique muscle than the myectomy.

(Br F Ophthalmol 1999;83:206-208)
\end{abstract}

Various weakening techniques for an overactive inferior oblique muscle have been suggested since Jones et $a l^{1}$ described myotomy for the first time. These include disinsertion, myotomy, recession, denervation-extirpation, myectomy, and anterior transposition. ${ }^{23}$ The latter two were mainly performed when inferior oblique muscle overaction is +3 .

For recession, although the persistence of inferior oblique muscle overaction and recurrence appeared less than for myectomy, recessed inferior oblique muscle adhered well to the sclera and rarely moved to the insertion. Also, the operating time is longer than for myectomy and the techniques of approach are difficult in recession of inferior oblique muscle overaction. To overcome such difficulty a simple technique has been developed and used safely. ${ }^{4}$ However, for myectomy, the operation time is short and the technique is simple, but the muscle end which is removed reattaches so that the recurrence appears and the inferior oblique underaction frequently occurs.

Some surgeons approach the management of inferior oblique muscle overaction, by attaching the muscle anterior to the equator of the globe. Gobin ${ }^{5}$ popularised a technique, known as the anterior transposition and recession of the inferior oblique muscle. Scott ${ }^{6}$ suggested through his computer model that there were advantages of the inferior oblique anterior transposition, compared with the more classic recession technique. Elliott and Nankin ${ }^{7}$ first reported the specific attachment of the inferior oblique muscle immediately adjacent to the temporal margin of the insertion of the inferior rectus. They showed that it was effective for treating severe and recurrent inferior oblique muscle overaction. A subsequent report by Bremer et $a l^{8}$ emphasised the risk of this procedure producing hypotropia at the primary position in patients when used unilaterally for an overactive inferior oblique muscle secondary to fourth cranial nerve palsy.

This work presents a prospective study designed to compare the anterior transposition technique with the myectomy technique in patients undergoing surgery for +3 bilateral primary overactive inferior oblique muscles.

Materials and methods

All patients were selected, operated, and evaluated postoperatively and independently between 1 October 1990 and 31 December 1991. Twenty patients with no vertical deviation in primary position, but with symmetrical +3 bilateral inferior oblique muscle overaction, were treated with anterior transposition on one eye and myectomy on the other eye.

Excluded from the study were patients with prior inferior or vertical rectus muscle surgery, prior vertical offsetting of horizontal vertical muscles, mechanical restrictions, positive head tilt tests, dissociated vertical deviations, or cases requiring other vertical muscle surgery in addition to the inferior oblique. Twenty patients undergoing a simultaneous procedure on horizontal rectus muscles without vertical offsets were included. Specifically, 14 were esotropic patients with $30-50$ prism dioptres (averaging 37.5 prism dioptres), others were intermittent exotropic ones, who showed 20-30 prism dioptres (averaging 25.0 prism dioptres). There were nine male and 11 female patients studied, ranging in age at surgery from 3 to 12 years with an average of 6 years. V patterns were frequents, and showed 5-15 prism dioptres (averaging 12.0 prism dioptres) in this 
Table 1 Frequency of apparent residual overacting inferior oblique muscles and consecutive underacting inferior oblique muscles following anterior transposition and myectomy on 20 patients in inferior overaction

\begin{tabular}{llc}
\hline & $\begin{array}{l}\text { Anterior } \\
\text { transposition }\end{array}$ & Myectomy \\
\hline Residual overaction & $2(0 \%)$ & $15(75 \%)$ \\
Consecutive underaction & $1(5 \%)$ & $0(0 \%)$ \\
\hline
\end{tabular}

study group of patients. The preoperative and postoperative binocular alignment, and motility assessment included alternate prism and cover measurements in the primary position at distance and near, and distant midline upgaze and downgaze. The function of the oblique muscles was studied by comparing the coordinated movement of the two eyes in the cardinal fields of gaze, up and right, up and left, down and right, and down and left. Oblique muscle dysfunction was graded in the approximately $45^{\circ}$ adducted eye on a nine point scale from -4 underaction to +4 overaction. For this the fixating abducted eye first remained elevated approximately $30^{\circ}$ above mid-level and then lowered to approximately $30^{\circ}$ below mid-level. The underactions and overactions of the oblique muscles were graded in approximately $7^{\circ}$ increments. For example, the adducted eye with a +3 overactive inferior oblique muscle would be approximately $21^{\circ}$ upturn than the adducted fixating eye.

A random selection scheme dictated the specific surgical technique to be followed for each patient and was not disclosed to the surgeon until he was making the conjunctival incision.

The specific technique used for each eye was not recorded in the surgeon's office record. Rather, this information was forwarded to the other author for retention until the end of the study, with the intention of trying to mask the surgeon from the knowledge of the specific procedure. The technique was performed on either eye during the postoperative measurements and evaluations were made by the operating surgeon. At the conclusion of the study, copies of the office records were exchanged

Table 2 Inferior oblique muscle action following anterior transposition and myectomy

\begin{tabular}{llllll}
\hline \multicolumn{5}{l}{ Follow up period } \\
\cline { 2 - 6 } Surgical method & 1 Day & 1 Month & 6 Months & 1 Year & 2 Years \\
\hline Anterior transposition & $0.21(0.42)$ & $0.04(0.14)$ & $0.04(0.14)$ & $0.10(0.31)$ & $0.10(0.31)$ \\
Myectomy & $-0.31(0.44)$ & $0.85(0.80)$ & $0.89(0.74)$ & $1.20(0.64)$ & $1.18(0.65)$ \\
p Value & 0.06 & 0.01 & 0.01 & 0.0001 & 0.0001 \\
\hline
\end{tabular}

Scale: -4 underaction to 0 normal to +4 overaction.

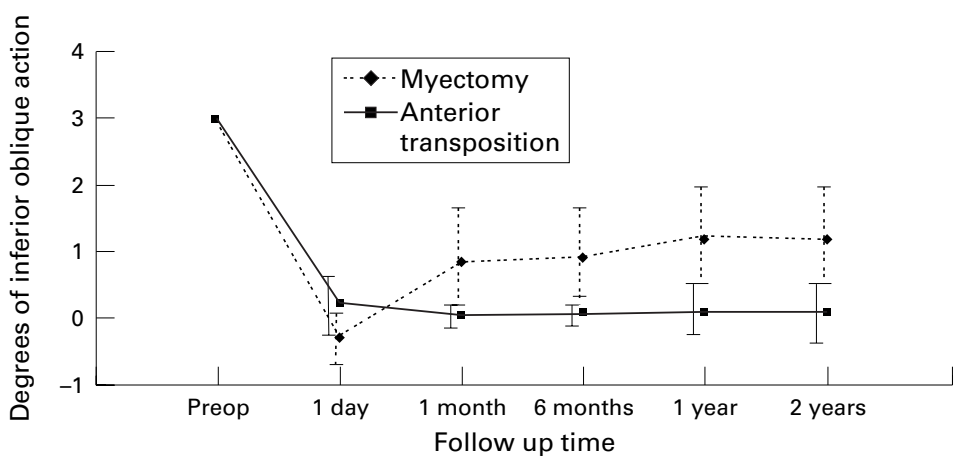

Figure 1 Inferior oblique action following anterior transposition and myectomy. and each surgeon analysed the results of the other's patients. The postoperative follow up which averaged 2 years, ranged from 1 year 3 months to 4 years 4 months. Bilateral horizontal rectus surgery was performed simultaneously with the inferior oblique muscle surgery in all 20 cases; specifically, medial rectus muscle in 14 and lateral rectus muscle in six. Eleven patients underwent anterior transposition on their right inferior oblique and myectomy on their left inferior oblique. The reverse of these procedures was performed in the other nine patients.

Both operations used the fornix incision to separate the inferior oblique muscle from the surrounding tissue. The myectomy was performed to remove the segment of the inferior oblique muscle which was lying between two haemostats which were placed $7 \mathrm{~mm}$ apart from the insertion and at the muscle stump. To prevent bleeding, the end of the removed muscle was cauterised. The anterior transposition removed the separated inferior oblique muscle at the insertion and the ends were tied together with 6-0 Vicryl and made to readhere to the sclera on the lateral boundary $1 \mathrm{~mm}$ back from the insertion.

\section{Results}

The final follow up assessment of the versions revealed a significant difference in the apparent function of the inferior oblique muscles between the eyes with anterior transposition and those with myectomy. The frequency of these apparent abnormal inferior oblique muscle functions resulting from these two different surgical techniques is presented in Table 1. Residual overaction was observed in two eyes $(10 \%)$ after anterior transposition and in 15 eyes $(75 \%)$ after myectomy. The consecutive underaction was observed in only one eye after anterior transposition.

The inferior oblique action became close to the normal after anterior transposition, which showed statistically better results than myectomy (Table 2, Fig 1). Comparing the degree of the inferior oblique action between the two operation methods with the figure according to the period of follow up, there was no large difference between the two methods at 1 day after the operation. However, a little overaction appeared on the myectomy.

The eyes with anterior transposition showed relatively stable inferior oblique action postoperatively, but the eyes with myectomy exhibited underaction of the inferior oblique muscle on postoperative day 1 . The latter showed residual overaction from the postoperative month 1 .

Only five patients at the final follow up assessment had no oblique muscle dysfunction in either eye. The remaining 15 had abnormal inferior oblique muscle results manifested by either apparent residual overaction or consecutive underaction (Table 3).

The sum of all the apparent inferior oblique muscle dysfunction for the eyes with anterior transposition averaged to +0.1 residual overaction per eye compared with an average +1.2 residual overaction for eyes after myectomy 
Table 3 Postoperative inferior oblique muscle function for anterior transposition compared with myectomy

\begin{tabular}{lll}
\hline & \multicolumn{2}{c}{ Procedure } \\
\cline { 2 - 3 } $\begin{array}{l}\text { Postoperative inferior } \\
\text { oblique muscle function }\end{array}$ & $\begin{array}{l}\text { Anterior } \\
\text { transposition }\end{array}$ & Myectomy \\
\hline+2 & 2 & 9 \\
+1 & 17 & 6 \\
0 & 1 & 5 \\
-1 & & \\
\hline
\end{tabular}

$(\mathrm{p}=0.0001)$. No patient had pre- and postoperative overaction of the superior oblique muscles. Limited midline elevation was observed in only one eye receiving the anterior transposition surgical technique. The different inferior oblique muscle weakening surgical techniques produced a hypotropia of 3 prism dioptres at the primary position in one eye after anterior transposition.

In 14 esotropic patients, horizontal deviation from 0 to residual 20 prism dioptres (averaging 7.5 prism dioptres) was observed, while in the other exotropic ones, the horizontal deviation was from 0 to 10 prism dioptres (averaging 3.5 prism dioptres). $\mathrm{V}$ patterns showed from 0 to 5 prism dioptres (averaging 2.0 prism dioptres).

\section{Discussion}

Both anterior transposition and myectomy reduced the function of the overactive inferior oblique muscle, but eyes with anterior transposition tended to be more effective. At postoperative day 1, the eyes with myectomy showed underaction of the inferior oblique muscle, which is probably due to non-attachment of the inferior oblique muscle to the globe. Also, the residual overaction shown from the postoperative month 1 meant the inferior oblique muscle had reattached to the globe. On the other hand, for eyes with anterior transposition stable action was observed postoperatively. Only one eye in the anterior transposition manifested a limited elevation in midline, adduction, and abduction, the magnitude of which is less than that given by other published data. ${ }^{78}$ In the eyes with anterior transposition, the inferior oblique muscles were reattached to the sclera at $1 \mathrm{~mm}$ recessed from the lateral boundary of the insertion of the inferior rectus, which is less anterior than other reported anterior transpositions.

There are studies on the difference between two inferior oblique muscle weakening procedures. Elliott and Nankin ${ }^{7}$ compared the anterior transposition with the inferior oblique muscle recession, and Del Monte and Parks ${ }^{9}$ compared the denervation-extirpation on one eye with the " $14 \mathrm{~mm}$ " recession of the inferior oblique muscle on the other eye in 16 patients with bilateral symmetrical +4 primary inferior oblique muscle overaction. Their results at the final assessment showed 100\% normal inferior oblique muscle action for the denervationextirpation eyes, while $88 \%$ of the eyes receiving the recession had a residual +1 to +4 overactive inferior oblique muscle. In our study for +3 inferior oblique muscle overaction, the anterior transposition procedure resulted in $85 \%$ normal inferior oblique muscle action, while the myectomy procedure resulted in $25 \%$ normal inferior oblique muscle action and $75 \%$ residual inferior oblique muscle overaction.

Hypotropia occurred in only one of 20 eyes with anterior transposition. Bremer et $a l^{8}$ speculated that the reason for the hypotropia following the anterior transposition technique was that the inferior oblique muscle conversion had a depressor function. Neither anterior transposition nor myectomy affected the function of the superior oblique muscle, which is a direct antagonist of the inferior oblique muscle. Each technique equally reduced every underaction of the superior oblique muscles present preoperatively. Eleven of the 20 patients preoperatively had either reduced (three patients) or eliminated (eight patients) symmetrical bilateral superior oblique muscle underaction. In fact, no difference was detected in the way that these two techniques affected the alignment of the eye in downgaze.

From this study, we concluded that the anterior transposition technique effectively eliminated the overaction in adduction of the +3 overacting inferior oblique muscle. The limited elevation of the anterior transposition eye is less-only 1 . Neither technique affected the vertical action of the superior oblique muscle in downgaze.

This work was presented in part at the annual meeting of Association for Research in Vision and Ophthalmology, Fort Lauderdale, Florida, May 1995.

1 Jones TW, Lee DA, Dyer JA. Experience at the Mayo Clinic from 1960 to 1981. Arch Ophthalmol 1984;102:714-16.

2 Gonzalez C. Denervation of the inferior oblique (as a weakening surgical procedure). Trans Am Acad Ophthalmol Otolaryngol 1974;78:816-23.

3 Helveston EM, Haldi BA. Surgical weakening of the inferior oblique. Int Ophthalmol 1976;16:113-26.

4 Gillies WE. Simple technique for recession of the inferior oblique muscle. Br f Ophthalmol 1970;54:736-9.

5 Gobin MH. Cyclotropia and squint. Antwerp: Krol and Courtin, 1969;Ch 2:12-16.

6 Scott AB. Planning inferior oblique muscle surgery. In: Third international strabismus symposium. New York: Grune and Stratton, 1978:347-54.

7 Elliott RL, Nankin S. Anterior transposition of the inferior oblique. I Pediatr Ophthalmol Strabismus 1981;18:35-8.

8 Bremer DL, Rogers L, Quick LD. Primary-position hypotropia after anterior transposition of the inferior oblique. Arch Ophthalmol 1986;104:229-32.

9 Del Monte MA, Parks MM. Denervation and extirpation of the inferior oblique: an improved weakening procedure for marked overaction. Ophthalmology 1983;90:1178-85. 